\title{
CORRESPONDENCE
}

Self poisoning in 1984: a prediction that didn't come true

C Brewer, MRCPSYCH, and R Farmer, MFCM 391

Why do our hospitals not make more use of the concept of a trauma team?

A R Luksza, MRCP; D Ferguson, FRCSED, and others; Jacky Chambers, MB....... 392

Diagnosis by postmortem blood sampling

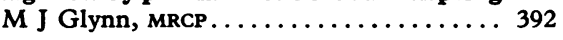

NHS theek hai?

J Carnie, FFARCS, and B Kumar, fFarcs;

R Bhopal, MRCP.................. 392

What can we do about measles?

A Walling, MRCGP, and Anne Walling, MFCM 393

The rules of the game

B Freeman . . . . . . . . . . . . . . . . . . . 393
"Tissue thyrotoxicosis"

Jayne A Franklyn, MRCP, and M C Sheppard, MRCP; P B S Fowler, FRCP; W D Fraser, MB, and others................... 393

Fast neutron treatment for malignant tumours of the facial area

A Narula, FRCS, and others; $O H$ Shaheen, FRCS; Mary Catterall, FRCR, and others;

A Green, FRCR. . . . . . . . . . . . . . . . . . 394

Luteinising hormone releasing hormone analogue for prostatic cancer

M C Taylor, FRCSED; G Williams, fRCS. . . 395

Lung biopsy

S J Steel, FRCP................. 396

New concepts in incontinence

Nigel Smith, MRCP ................. 396
Teenage confidence and consent

P Schutte, MRCGP; Anonymous; D S Irvine, MB; R Vallance, FRCR............. 397 Pathology laboratories,

management, and the future

A D Farr, PHD...................... 397

First clinical use of penicillin

R Lawrie, MD................. 397

Points Death or dialysis (A $M$ Davison);

Clinical algorithms: infertility (D Carr-

Locke; P Bannister; G T Watts); Prevalence

of migraine in patients with diabetes

(M Lavin); An exploding haggis (A H

Duncan); Measles, mumps, and rubella

(C Claoue and Katherine Stevenson);

Corticosteroids and peptic ulcer ( $G$ W

Hanks); On the acquisition of a gastroscope

(M Eastwood); Setting the record a little

straighter (M O'Donnell) ............. 398

Because we receive many more letters than we have room to publish we may shorten those that we do publish to allow readers as wide a selection as possible. In particular, when we receive several letters on the same topic we reserve the right to abridge individual letters. Our usual policy is to reserve our correspondence columns for letters commenting on issues discussed recently (within six weeks) in the BMF.

Letters critical of a paper may be sent to the authors of the paper so that their reply may appear in the same issue.

We may also forward letters that we decide not to publish to the authors of the paper on which they comment.

Letters should not exceed 400 words and should be typed double spaced and signed by all authors, who should

include their main degree.

\section{Self poisoning in 1984: a prediction that didn't come true}

SIR,-In 1977, observing the trends in admissions for self poisoning, Jones predicted that if they continued every acute medical bed then existing would be filled with a self poisoner by 1984. His calculations were correct but the trends did not continue. As the figure shows, they peaked in 1977 and have fallen steadily almost every year since, along with the number of fatal suicidal poisonings. So have the numbers of fatal accidental and undetermined poisonings from solids and liquids (although they are not shown in the figure).

This sharp fall in the incidence of overdoses is without peacetime precedent. There may be more than one explanation, but we suggest that the most important and likely cause is that since 1976 the annual number of prescriptions for hypnotics and tranquillisers has also fallen steadily (see figure). Inevitably these drugs, so popular for overdoses, are preferentially prescribed for precisely the sort of patients and households among whom self poisoning is most common. If, for whatever reason, their availability is reduced fewer people will be able to take overdoses of them. That they will not necessarily use other drugs or methods is apparent from the decline in completed suicide by all methods since 1981 , following a reduction in the rate of increase since 1979, despite high unemployment. ${ }^{2}$

We suggest a parallel with the progressive removal of carbon monoxide from domestic gas and the subsequent disappearance of coal gas poisoning, which caused such a sharp decline in the British suicide rate from 1963 to 1975. These findings add to the evidence that self poisoning, like alcohol abuse, is influenced much more by external factors which are sometimes controllable, such as availability, than by internal, pathological ones such as "depressive illness," and that successful and attempted suicides are not "separate but overlapping" groups but form a continuum. (Similarly, it is difficult to believe that the US suicide rate would still be nearly twice the British onehalf of it by shooting-if firearms were not so easily available there.)

We will risk a new prediction for 1994: that changes in the indices of self poisoning will continue to reflect changes in the availability of prescribed sedatives and other

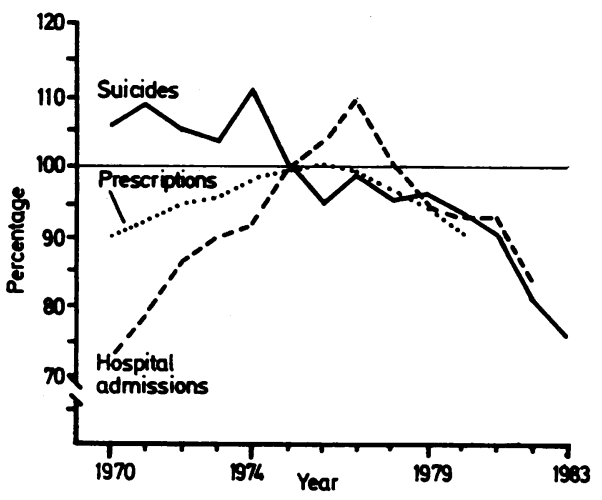

Hospital admissions for adverse effects of medicinal agents, suicide by solid or liquid substances, and numbers of prescriptions for hypnotics and tranquillisers, al expressed as percentage of 1975 level. Sources: OPC and Personal Social Services Statistics for England. psychoactive drugs. These figures and our explanation of them challenge some fashionable theories about the nature and prevention of suicidal behaviour. We believe they should also cause both doctors and patients to question even more seriously the elevation of human unhappiness to the status of a disease requiring medication, which has been such a feature of the past 25 years.

Community Alcoholism Treatment Service

COLIN BREWER

RICHARD FARMER

Department of Community Medicine, Westminster Hospital

1 Jones DIR. Self poisoning with drugs: the past 20 years in Sheffield. Br Med $¥ 1977 ; \mathrm{i}: 28-9$. Office of Population Censuses and Surveys. Annual reports. London: HMSO.

Why do our hospitals not make more use of the concept of a trauma team?

SIR,-I commend Mr J D Spencer on the organisation of a trauma team to facilitate the rapid resuscitation of patients with multiple injuries (12 January, p 136). In our own district the methods adopted to improve the care of the injured differ from Mr Spencer's but have also proved effective.

An internal survey conducted in 1977 showed alarming deficiencies in the standard of care of patients with multiple injuries. Critically ill patients often remained in the 
casualty department for long periods while different doctors $x$ rayed different parts of their anatomy without relieving pain or correcting shock. All resuscitation was taken over by the medical divison, and treatment was administered using standardised methods. ${ }^{12}$ As the casualty officers constituted a rapidly changing population the onus of responsibility for recognising severe injuries and alerting the intensive care specialist fell on the nursing staff, many of whom had undergone the English Nursing Board intensive care course. To facilitate immediate resuscitation a series of algorithms was constructed and displayed prominently in the casualty department.

The second hospital in our district is much smaller ( 300 beds) and has a correspondingly smaller resident staff. Our survey had shown even greater deficiencies at this hospital with an absence of the necessary skilled staff. The setting up of a trauma team in a hospital of this size was impracticable. An alternative solution was developed, which required all prospective casualty officers first to rotate through the medical department, where they were taught to recognise severe injuries and institute treatment.

A R Luksza

Intensive Care Unit and Clinical Research

Laboratory,

Whiston Hospital,

1 Jones ES, ed. Intensive care. Lancaster: MTP Press, 1982 .
Btoddart JC. Trauma and the anaesthetist. London:
Tindall, 1984.

SIR,-We congratulate Mr J D Spencer on his enthusiasm in organising the trauma team to fill a gap in the care of the seriously injured which existed in his hospital. However, we would question whether this is the best way to care for such patients in every hospital. In six months the trauma team cared for 15 patients. Assuming that the registrars are on duty for the trauma team one day in three, each registrar would see five patients in the six months. In most district general hospitals the registrars rotate every six or 12 months, so the experience that they accumulate must be rather limited. Also these registrars, although experienced in their own specialty, may have had little specific training in dealing with severe injury.

We agree that the reception of severely ill patients should not be left to a single junior in the accident department. Many district hospitals in Britain now have accident and emergency consultants, however, and teaching centres have senior registrars training in accident and emergency. Part of this training is directed to the immediate care and assessment of the multiply injured, and most of these doctors will already have had considerable experience of dealing with such problems.

Our opinion is that there should be a single experienced person in charge of these difficult injuries, and such a person should be able quickly to assess the patient, carry out resuscitation, decide treatment priorities, and ask for specialist help as required. This person should be a person with formal training in accident and emergency.

D Ferguson

D EDBROOKE

J WARDROPE

A Courtney Crosby

Accident and Bmergency Department,

Royal Hallamshire Hospital,

Sheffield S10 2JF
SIR,-However stimulating may be the concept of a trauma team proposed by Mr J D Spencer, the suggestion that each department should produce a second on call list of registrars to cover normal working hours or to substitute at night or weekends for other experienced junior staff until the surgical and orthopaedic registrars are free is totally unrealistic. For those of us who work outside the Thames Regions, where junior staffing levels consistently remain $10-20 \%$ below the national average, and face the prospect of staffing the first line accident, trauma, and orthopaedic services in our new district general hospitals without any registrar cover whatsoever such a proposal might arouse more than just general interest.

While consultant and junior staff working in some departments may be able to afford the luxury and time of writing articles for the British Medical fournal and taking part in a plethora of different teams, others are desperately struggling for permission to employ any experienced hospital junior staff at all. Let us hope that members of the Central Manpower Committee, the DHSS, and the newly formed joint planning advisory committee will sit up and take note of the real implications of such articles and, furthermore, go on to make firm recommendations about the redistribution of junior posts between regions which will boost morale and improve patient care in those areas of the service where it is needed most.

JACKy Chambers

West Midlands Regional

Birmingham B16 9PA

\section{Diagnosis by postmortem blood} sampling

SIR,-The report of Drs $S$ Leadbeatter and D Stansbie (15 December, p 1656) of a case in which the postmortem diagnosis of familial hypercholesterolaemia had profound implications prompts me to report another case in which postmortem blood sampling led to a diagnosis with important implications for the relatives and others.

A 19 year old man was brought to the casualty department, Southend General Hospital, with cardiorespiratory arrest having collapsed at home at 0550 . He had had a bad cold with a sore throa for four days and on the previous evening had complained of vomiting, diarrhoea, and extreme malaise. At midnight his parents had noticed a large bruise on his left hip and a mottled rash on his face and upper trunk. His parents had been woken by the patient groaning, and he suffered a cardiorespiratory arrest shortly after the arrival of the general practitioner and the ambulance. Cardiopulmonary resuscitation was performed during the journey to hospital and was continued in the casualty department. Sinus rhythm was induced for a short period, but cyanosis was not reversed, and there was no spontaneous respiration. Irreversible asystole followed, and resuscitation was abandoned after a total of $\mathbf{4 0}$ minutes.

Because of the purpuric rash present over the upper part of the body and the history of upper respiratory tract infection leading to rapid demise and death a diagnosis of meningococcal septicaemia was considered. A postmortem blood culture sample was taken using an intracardiac needle and subsequently grew Neisseria menin gitidis group B. Postmortem examination showed that the brain was intensely congested and the adrenal glands showed intense haemorrhage.

The rapid diagnosis of the specific pathogen causing this overwhelming iilness-namely the meningococcus-allowed prompt prophylaxis to be administered to all the contacts, particularly the patient's parents and all those concerned in the resuscitation, especially those who had performed mouth to mouth respiration. The prophylactic regimen currently recommended by the Central Public Health Laboratory is rifampicin $600 \mathrm{mg}$ twice daily for two days, which has been shown to be effective in eliminating the carrier state. ${ }^{1}$ Since the incubation period of meningococcal disease is short, prophylaxis should be started as early as possible, and in this case this was made possible by the use of postmortem blood samples.

M J GLYNN

Charing Cross Hospital,
London W6 8RF

1 Devine LF, Johnson DP, Rhode SL, Hagerman CR, Pierce WE, Peckinpaugh RO. Rifampicin: effect of two-day treatment on the meningococcal carrie state and the relationship to the levels
saliva. Am $\mathcal{Y}$ Med Sci 1971;261:79-83.

\section{NHS theek hai?}

SIR,-The leading article by Dr John A Black highlights the difficulties facing the medical profession and ethnic minorities in Britain regarding the availability of medical care. We share Dr Black's view that there is a special need to educate Asians about the facilities available to them.

The West Midlands region has the highest recorded number of births in England and Wales to mothers born in the New Commonwealth and Pakistan. ${ }^{1}$ The problem of communication results in difficulty in advising these women on an appropriate method of analgesia for their labour. Last year we studied the use of analgesia for labour pain relief in Asian primigravidas. During the period of the study there were 213 births, 181 to Caucasian and 32 to Asian mothers. The two groups had a similar-duration of labour and no major differences in the course of their labours (see table). There were,

Details of analgesia in labour. Values are means (and SE)

\begin{tabular}{|c|c|c|c|}
\hline & $\begin{array}{l}\text { Caucasian } \\
(\mathrm{n}=181)\end{array}$ & \multicolumn{2}{|c|}{$\begin{array}{c}\text { Asian } \\
(\mathbf{n}=\mathbf{3 2})\end{array}$} \\
\hline Duration of labour (h) & $9.9(0.5)$ & $12 \cdot 4$ & $(1 \cdot 6)$ \\
\hline $\begin{array}{l}\text { Time on labour ward betore } \\
\text { first analgesia }(\mathrm{h})\end{array}$ & $2.0(0.2)$ & & $(0 \cdot 2)$ \\
\hline $\begin{array}{l}\text { \% Of entire labour analgesia } \\
\text { given }\end{array}$ & $43 \cdot 0(5 \cdot 2)$ & $40 \cdot 0$ & $(\mathbf{1 1} \cdot \mathbf{2})$ \\
\hline $\begin{array}{l}\text { \% Given analgesia: } \\
\text { Pethidine } \\
\text { Epidural } \\
\text { Entonox } \\
\text { None }\end{array}$ & $\begin{array}{rc}43 & (3.7) \\
39 & (3.6) \\
10 & (2.2) \\
7 & (1.8)\end{array}$ & $\begin{array}{r}67 \\
22 \\
0 \\
9\end{array}$ & $\begin{array}{l}(8 \cdot 0) \\
(7 \cdot 3) \\
(5 \cdot 1)\end{array}$ \\
\hline
\end{tabular}

however, considerable differences in the methods of analgesia used. The differences between the Asians and the Caucasians were significant for the use of epidural analgesia $(p>0.05)$ and for intramuscular pethidine (p $>0.001$ )

The incidence of epidural use in Asians was half that in the Caucasians (see table). A greater use of epidurals for obstetric analgesia and for operative procedures has been advocated. ${ }^{2}$ Most of the Asian mothers received intramuscular pethidine, an inadequate analgesic in labour. ${ }^{3}$ Asian women with a poor knowledge of English are further disadvantaged since interpreters are readily available only during office hours.

If Asian mothers are to receive appropriate education interpreter services should be 